\title{
Analisis Faktor Penyebab Perilaku Seksual Pranikah pada Remaja di Desa Wedomartani Sleman Yogyakarta
}

\author{
1Suwarsi \\ 1Prodi S1 IImu Keperawatan FIKES UNRIYO Jalan Raya Tajem Km 1,5, Maguwoharjo, Depok, Kecamatan \\ Sleman, Daerah Istimewa Yogyakarta \\ Email: umisuwarsi@gmail.com
}

\begin{abstract}
Abstrak
Hasil studi pendahuluan yang dilakukan tanggal 3 Oktober 2014 di wilayah Desa Wedomartani melalui tokoh masyarakat didapatkan data bahwa remaja di Desanya sering menggunakan hand phone yang modern, remaja mengakses informasi yang berkaitan dengan perilaku seksual. Tahun 2014 di Desa Wedomartani ada 1 siswa yang dikeluarkan karena kasus seksual pranikah yang mengakibatkan kehamilan tidak diinginkan. Tujuan penelitian untuk mengetahui faktor penyebab perilaku seksual pranikah pada agregat remaja di Desa Wedomartani Sleman. Penelitian kuantitatif dengan metode penelitian analitik menggunakan uji chi-square, dengan sampel sebanyak 80 remaja. Hasil karakteristik umur remaja di Desa Wedomartani Sleman yang pernah berperilaku seks bebas berada dari rentang umur 12 tahun sampai 26 tahun, dengan mayoritas usia 20 tahun (25\%). Karakteristik keterpaparan tentang seks bebas melalui media TV mayoritas berada pada kategori tidak beresiko (55\%), sedangkan remaja yang beresiko terpapar seks bebas melalui media TV sebanyak 45\%. Karakteristik remaja yang pernah mengakses pornografi melalui media Internet sebanyak 45 remaja atau 56,3\%. Kesimpulan keterpaparan tontonan TV yang beresiko dan pernah mengakses pornografi dari internet memiliki hubungan yang bermakna terhadap perilaku seksual pranikah pada remaja di Desa Wedomartani Sleman.
\end{abstract}

Kata Kunci: internet, perilaku seksual pranikah, remaja, televisi

\section{Analysis of Causing Factors of Adolescents Sexual Behavior in Wedomartani Village, Sleman, Yogyakarta}

\begin{abstract}
The results of a preliminary study that was conducted on October 3, 2014 in the working area through community leaders that the data obtained in the region find teenagers who use modern mobile phone is already making it easier for adolescents to access information related to sexual behavior. In 2014 there was one case of students expelled because of unwanted pregnancies. The purpose of study was to determine the factors that causing the premarital sexual behavior in adolescents in Wedomartani village, Sleman. Study methods used was quantitative with analytical research using chi-square test, with a sample of 80 adolescents. The results showed that characteristics of teens in the village of Sleman Wedomartani ever be free of sexual behavior lifespan of 12 years to 26 years, with the majority age of 20 years (25\%). Characteristics of free sex through exposure on TV media majority were at no risk category (55\%), whereas the risk of exposure to teenage promiscuity through TV media as much as 45\%. Characteristics of adolescents ever accessing pornography through the Internet as much as 45 teenagers or $56.3 \%$. In conclusions, there was significant relationship between TV exposure and accessing pornography on the Internet toward adolescents premarital sexual behavior in the Wedomartani village of Sleman.
\end{abstract}

Keywords: internet, premarital sexual behavior, adolescents, television

Info Artikel:

Artikel dikirim pada 23 Januari 2016

Artikel diterima pada 20 Februari 2016

DOI : http://dx.doi.org/10.21927/jnki.2016.4(1).39-43 


\section{PENDAHULUAN}

Upaya antisipasi yang baik terhadap masalah yang muncul pada remaja dapat mencegah terjadinya berbagai masalah kesehatan remaja. Antisipasi tersebut salah satunya dengan cara mengenali karakteristik remaja sebagai kelompok beresiko (population at risk). Stanhope dan Lancaster, menyebutkan bahwa karakteristik berisiko (at risk) mencakup risiko biologik dan usia; sosial; ekonomi; lingkungan; gaya hidup; dan kejadian dalam hidup. Kondisi yang membuat remaja menjadi kelompok berisiko dari aspek biologis dan usia adalah perubahan yang sangat cepat pada remaja(1).

Edelman dan Mandle dalam Perry dan Potter, menyebutkan bahwa perubahan kondisi fisik pada remaja adalah ketika remaja memasuki masa pubertas, menstruasi pertama pada remaja putri dan perubahan suara pada remaja putra $(2,3)$. Pada remaja yang sudah puber, produksi hormon menjadi aktif. Hormon aktif tersebut adalah folliclestimulating hormone ( $\mathrm{FSH}$ ) dan luteinizing hormone (LH). Perbedaan perubahan hormonal pada tiap remaja berdampak pada perbedaan pertumbuhan yang terjadi pada remaja. Remaja yang tumbuh lebih lambat dibandingkan dengan remaja lain cenderung merasa malu dan minder, sebaliknya remaja yang tumbuh cepat, berbadan besar akan merasa kuat dan hebat sehingga terkadang remaja tersebut merasa menjadi jagoan. Perbedaan pertumbuhan ini dapat menimbulkan masalah pada remaja.

Berdasarkan survey yang dilakukan BKKBN (Badan Koordinasi Keluarga Berencana Nasional) tahun 2008 menyatakan $63 \%$ remaja di kota besar di Indonesia telah melakukan seks pranikah(4). Data nasional menunjukan bahwa kurang lebih setengah dari seluruh remaja masa kini telah melakukan hubungan seks sejak usia 18 tahun(5). Penelitian dari Lembaga Studi Cinta dan Kemanusiaan serta Pusat Penelitian Bisnis dan Humaniora (LSCK-PUSBIH) di tahun 2008 terhadap 1.660 remaja putri di Yogyakarta didapatkan 97,05\% remaja putri di Yogyakarta sudah hilang kegadisannya dan 98 orang mengaku pernah melakukan aborsi(6). Jalal, menyebutkan bahwa seks pranikah merupakan masalah utama yang terjadi pada remaja(7).

Hasil Riskesdas, menggambarkan bahwa umur pertama kali berhubungan seksual sebelum menikah laki-laki dan perempuan 10-24 tahun, dengan $38 \%$ perempuan mengatakan hubungan seksual terjadi begitu saja, sedangkan $58 \%$ laki-laki merasa penasaran, $13 \%$ remaja putri melakukan seks pranikah karena paksaan(8). Persentase remaja putri 15-19 tahun yang sudah melahirkan dan hamil anak pertama naik dari 8,5\% dari tahun 2007 menjadi 9,5\% pada tahun 2012 . Terdapat $10 \%$ remaja putri $15-19$ tahun telah menjadi ibu(9).

Tingginya persentase remaja yang melakukan seks pra nikah, hamil muda dan menjadi ibu muda, maka Pemerintah melalui UU RI NO 52 Tahun 2009 Tentang Perkembangan Kependudukan dan Pembangunan Keluarga Pasal 48 no 1 point b, menyebutkan bahwa kebijakan pembangunan keluarga melalui pembinaan ketahanan dan kesejahteraan keluarga; peningkatan kualitas remaja dengan pemberian akses informasi, pendidikan, konseling, dan pelayanan tentang kehidupan berkeluarga(10).

Hasil dari studi pendahuluan yang dilakukan tanggal 3 Oktober 2014 di Wilayah kerja Puskemas Ngemplak melalui beberapa tokoh agama didapatkan data bahwa di wilayah Ngemplak sering dijumpai remaja yang menggunakan hand phone yang sudah modern sehingga memudahkan para remaja mengakses informasi dari luar. Pada tahun 2014 ada 1 siswa yang dikeluarkan karena kasus kehamilan yang tidak diinginkan (KTD), belum dilaksanakannya penyuluhan tentang HIVIAIDS, seks bebas dan dampak dari perilaku seks bebas baik dari Pusat Informasi dan Layanan Remaja (PILAR), Perhimpunan Keluarga Berencana Indonesia (PKBI), Badan Koordinasi Keluarga Berencana Nasional (BKKBN), Puskesmas dan Dinas Kesehatan setempat. Hasil studi pendahuluan, terhadap 11 remaja dari 250 remaja didapatkan sebanyak 7 orang remaja berpacaran, dan 4 orang remaja belum pernah berpacaran, dari hasil wawancara 6 orang remaja tidak tahu apa itu perilaku seks pada remaja, dan dampak perilaku seksual pranikah, 5 remaja tidak peduli akan hal itu.

\section{BAHAN DAN METODE}

Jenis penelitian yang dilakukan pada penelitian ini yaitu penelitian kuantitatif dengan metode penelitian analitik korelasi dengan menggunakan desain rancangan cross sectional. Sampel penelitian berjumlah 80 remaja yang berada di Desa Wedomartani, Sleman Yogyakarta, dengan kriteria inklusi sebagai berikut: Remaja di Desa Wedomartani, Sleman Yogyakarta, bersedia menjadi responden, belum menikah, umur 15-21 tahun. Teknik sampling yang digunakan adalah teknik probability sampling dan simple random sampling. Instrument berupa kuesioner yang terdiri dari kuesioner tentang paparan media TV, media Internet dan kuesioner perilaku seks bebas yang telah diuji validitas dan reliabelitas. Hasil uji validitas dan reliabelitas dinyatakan valid dengan tiap pertanyaan memiliki nilai t hitung lebih dari t table $(0,361)$ dengan nilai cronbach alpha 0,8. Analisis bivariat dalam penelitian ini dengan uji statistik chi-square. 


\section{HASIL DAN BAHASAN}

\section{Karakteristik Responden Remaja}

Karakteristik responden remaja yang disajikan dalam penelitian berupa karakteristik jenis kelamin, yang disajikan pada Tabel 1.

Tabel 1. Distribusi Frekuensi Berdasarkan Jenis Kelamin Remaja Berperilaku Seksual Pranikah di Desa Wedomartani Kabupaten Sleman, 2015

\begin{tabular}{lcc}
\hline Jenis Kelamin & $\mathbf{n}$ & $\%$ \\
\hline Laki-Laki & 64 & 80 \\
Perempuan & 16 & 20 \\
Jumlah & 80 & 100 \\
\hline
\end{tabular}

Berdasarkan Tabel 1 diketahui bahwa remaja yang pernah berperilaku seksual pranikah mayoritas adalah berjenis kelamin laki-laki sebanyak 64 remaja (80\%).

\section{Paparan Perilaku Seksual Pranikah Melalui Media TV}

Berikut penyajian keterpaparan perilaku seksual pranikah melalui media TV yang disajikan dalam Tabel 2.

Tabel 2. Distribusi Frekuensi Paparan Perilaku Seksual Pranikah Melalui Media Televisi (TV) pada Remaja di Desa Wedomartani Sleman Yogyakarta, 2015

\begin{tabular}{lcc}
\hline \multicolumn{1}{c}{ Keterpaparan Media TV } & $\mathbf{n}$ & \% \\
\hline Tidak Beresiko & 44 & 55 \\
Beresiko & 36 & 45 \\
Jumlah & 80 & 100 \\
\hline
\end{tabular}

Berdasarkan Tabel 2 dapat diketahui bahwa frekuensi keterpaparan remaja tentang seks bebas melalui media TV paling banyak berada pada kategori tidak beresiko (55\%), sedangkan remaja yang beresiko terpapar seks bebas melalui media TV sebanyak $45 \%$.

\section{Paparan Perilaku Seksual Pranikah Melalui Media Internet}

Berikut penyajian keterpaparan perilaku seksual pranikah melalui media internet yang disajikan dalam Tabel 3.

Tabel 3. Distribusi Frekuensi Paparan Pornografi Melalui Media Internet pada Remaja di Desa Wedomartani Sleman, Yogyakarta 2015

\begin{tabular}{lcc}
\hline Keterpaparan Pornografi & $\mathbf{n}$ & \% \\
\hline Tidak Pernah Terpapar & 35 & 43,7 \\
Pernah Terpapar & 45 & 56,3 \\
Jumlah & 80 & 100 \\
\hline
\end{tabular}

Berdasarkan Tabel 3 dapat diketahui bahwa remaja di Desa Wedomartani Sleman yang pernah mengakses pornografi melalui media Internet sebanyak 45 remaja atau $56,3 \%$.

\section{Kategori Perilaku Seksual Pranikah}

Berikut penyajian gambaran perilaku seksual pranikah pada remaja yang disajikan dalam Tabel 4.

Tabel 4. Gambaran Kategori Perilaku Seksual Pranikah pada Remaja di Desa Wedomartani Sleman, Yogyakarta, 2015

\begin{tabular}{lcc}
\hline \multicolumn{1}{c}{ Perilaku Seksual Pranikah } & $\mathbf{n}$ & \% \\
\hline Beresiko & 44 & 55 \\
Rentan & 36 & 45 \\
Jumlah & 80 & 100 \\
\hline
\end{tabular}

Kategori perilaku seksual pranikah berdasarkan Tabel 4 pada remaja di Desa Wedomartani Sleman paling banyak berada pada kategori beresiko sebanyak 44 remaja (55\%), sedangkan sisanya berada pada kategori rentan, yaitu 36 remaja atau $45 \%$ dari total 80 remaja.

\section{Hubungan Paparan Media TV dengan Perilaku Seksual Pranikah}

Berikut penyajian hubungan perilaku seksual pranikah pada remaja dengan keterpaparan media TV yang disajikan dalam Tabel 5 .

Tabel 5. Hubungan antara Paparan TV dengan Perilaku Seksual Pranikah Remaja di Desa Wedomartani Sleman, 2015

\begin{tabular}{lcccc}
\hline Keterpaparan & \multicolumn{2}{c}{ Perilaku } & \multirow{2}{*}{ Total } & p-value \\
\cline { 2 - 3 } TV & Berisiko & Rentan & & \\
\hline Tidak Berisiko & 38 & 6 & 44 & 0,000 \\
Berisiko & 6 & 30 & 36 & \\
Jumlah & 44 & 36 & 80 & \\
\hline
\end{tabular}

Berdasarkan Tabel 5 dapat diketahui bahwa remaja yang terpapar pada tontonan TV berisiko, memiliki kerentanan dalam berperilaku seks bebas dibandingkan dengan remaja yang tidak terpapar tontonan TV. Hasil $p$-value didapatkan 0,000 yang artinya ada hubungan yang bermakna antara keterpaparan tontonon TV yang beresiko dengan Perilaku seks bebas pada remaja di Desa Wedomartani Sleman.

\section{Hubungan Paparan Media Internet dengan Perilaku Seksual Pranikah}

Berikut penyajian hubungan perilaku seksual pranikah pada remaja dengan keterpaparan media internet yang disajikan dalam Tabel 6 . 
Tabel 6. Hubungan antara Mengakses Pornografi dalam Internet dengan Perilaku Seks Bebas pada Remaja di Desa Wedomartani Sleman Yogyakarta, 2015

\begin{tabular}{lcccc}
\hline $\begin{array}{c}\text { Keterpaparan } \\
\text { Pornografi } \\
\text { dalam Media } \\
\text { Internet }\end{array}$ & Beresiko & Rentan & Total & p-value \\
\cline { 2 - 4 } & & & & \\
\hline Tidak Pernah & 38 & 6 & 44 & 0,000 \\
Pernah & 6 & 30 & 36 & \\
Jumlah & 44 & 36 & 80 & \\
\hline
\end{tabular}

Berdasarkan Tabel 6 dapat diketahui bahwa remaja yang pernah mengakses pornografi dari internet, memiliki kerentanan dalam berperilaku seks bebas dibandingkan dengan remaja yang tidak pernah mengakses pornografi dari internet. Hasil Probabilitas didapatkan nilai 0,000 yang artinya ada hubungan yang bermakna antara pernah mengakses pornografi dari internet dengan Perilaku seks bebas pada remaja di Desa Wedomartani Sleman.

Kategori perilaku seks bebas pada remaja di Desa Wedomartani Sleman paling banyak berada pada kategori beresiko sebanyak 44 remaja (55\%). Remaja yang berisiko artinya bahwa remaja tersebut memiliki kecenderungan untuk berperilaku seksual. Berperilaku seksual adalah segala tingkah laku yang didorong oleh hasrat seksual, baik dengan lawan jenis maupun sesama jenis. Bentuk-bentuk tingkah laku ini dapat beraneka ragam, mulai dari perasaan tertarik hingga tingkah laku berkencan dan bersenggama. Perilaku seksual ialah perilaku yang melibatkan sentuhan secara fisik anggota badan antara pria dan wanita yang telah mencapai pada tahap hubungan intim, yang biasanya dilakukan oleh pasangan suami istri.

Lebih dari separuh pengguna internet remaja bersifat paparan negatif $(56,3 \%)$. Data ini tidak mengagetkan karena penggunaan internet saat ini yang didominasi oleh kalangan remaja kurang mendapat pengawasan dan kontrol. Media internet bagi remaja menjadi sumber segala informasi yang dibutuhkan termasuk hal-hal negatif, seperti pornografi. Paparan media internet adalah komponen teori HPM sebagai pengaruh situasional yang berupa kondisi lingkungan yang mampu menimbulkan pemicu (tringger action)(11).

Dampak penggunaan paparan media internet secara negatif dapat meningkatkan pola pikir remaja yang dipengaruhi oleh konten dari media internet. Konten pornografi dapat diperoleh secara mudah dari internet. Santrock, menyebutkan dari 1000 situs yang dikunjungi, 10 persen diantarnya berorientasi seks(12). Remaja yang terpapar pornografi, dapat menimbulkan rasa senang dan kecanduan. Kecanduan dengan pornografi akan menimbulkan keinginan untuk mempraktekkannya di kehidupannya. Media internet tidak akan bisa dihindarkan dalam kehidupan saat ini dan masa mendatang. Upaya yang dapat dilakukan untuk menekan dampak internet adalah memblokir konten pornografi, memberikan pelatihan diri, dan pendampingan dari orang tua, guru, dan orang disekitarnya agar ikut mengawasi dan mengontrol perilaku akses internet remaja.

Hasil penelitian mengenai paparan media TV didapatkan bahwa $45 \%$ termasuk dalam kategori terpapar media televisi yang beresiko. Remaja terpapar media televisi yang beresiko maksudnya adalah remaja memanfaatkan media TV yang dapat berdampak pada perilaku seksual pranikah. Terdapat hubungan yang signifikan antara paparan media TV dengan perilaku kenakalan remaja pada penelitian ini, dapat disebabkan karena menurut Santrock, media televisi memberikan rangsangan terus menerus dan baru sehingga menarik bagi remaja, media TV sebagai koping dimana remaja menggunakan media televisi untuk mengurangi kecemasan dan ketidakbahagiaan, dan media TV sebagai model bagi remaja dimana media televisi menghadirkan model pria dan wanita yang dapat mempengaruhi tingkahlaku dan perilaku remaja(12).

Media televisi berperan sebagai alat informasi, dimana dalam proses penyampaian isi pesan pada media televisi kepada pemirsa akan di interpretasikan berbeda-beda menurut visi pemirsa. Dampak yang akan ditimbulkan dari informasi tersebut akan berbeda-beda juga menurut visi pemirsa. Hal ini terjadi karena tingkat pemahaman dan kebutuhan pemirsa terhadap isi pesan acara televisi berkaitan erat dengan status sosial ekonomi serta situasi atau kondisi pemirsa saat menonton televisi(13). Berdasarkan pendapat tersebut maka remaja yang menonton TV yang menampilkan kekerasan atau kenakalan, bagi remaja yang pemahaman tentang isi dari sebuah acara atau tayangan tersebut kurang, maka remaja dimungkinkan hanya mengambil sebagian kecil dari perilaku yang ditampilkan dalam acara tersebut saja, maka dampak dari kurangnya pemahaman mengenai isi dari tayangan TV dapat berhubungan dengan munculnya perilaku remaja.

Hasil penelitian ini sejalan dengan penelitian Nuryani dan Pratami yang menyatakan bahwa bahwa ada hubungan yang signifikan antara keterpaparan media informasi tentang seks dengan perilaku seks pada remaja(14).

\section{SIMPULAN DAN SARAN}

Berdasarkan hasil dan bahasan didapatkan simpulan karakteristik remaja di Desa Wedomartani 
Sleman yang pernah berperilaku seksual pranikah mayoritas adalah berjenis kelamin laki-laki. Karakteristik keterpaparan remaja tentang seksual pranikah melalui media TV paling banyak berada pada kategori tidak beresiko (55\%), sedangkan remaja yang beresiko terpapar seks bebas melalui media TV sebanyak 45\%. Karakteristik remaja di Desa Wedomartani Sleman yang pernah mengakses pornografi melalui media Internet sebanyak 45 remaja atau $56,3 \%$, sedangkan sisanya 35 remaja tidak pernah mengakses pornografi melalui media internet. Remaja di Desa Wedomartani Sleman paling banyak berada pada kategori at risk, atau berisiko. sedangkan sisanya berada pada kategori rentan. Ada hubungan yang bermakna antara keterpaparan tontonon TV yang beresiko dengan Perilaku seks bebas pada remaja di Desa Wedomartani Sleman Yogyakarta. Ada hubungan yang bermakna antara pernah mengakses pornografi dari internet dengan Perilaku seks bebas pada remaja di Desa Wedomartani Sleman Yogyakarta.

Rekomendasi bagi Dinas Kesehatan Kabupaten Sleman agar dapat melakukan kerjasama dengan Dinas Pendidikan Kabupaten Sleman dalam rangka optimalisasi kegiatan remaja untuk meningkatkan potensi remaja dalam mengelola waktu luang remaja agar dapat meningkatkan potensi remaja dan meminimalkan perilaku seks bebas remaja. Perawat komunitas yang bekerja di Dinas kesehatan dapat merekomendasikan pada Dinas Perijinan dan Penyiaran Kabupaten Sleman dalam rangka pengelolaan media $\mathrm{TV}$, media internet yang tidak menyebabkan resiko perilaku seks bebas bagi remaja serta sanksi yang jelas bagi yang melanggar. Bagi puskesmas dapat melaksanakan pelayanan kesehatan peduli remaja di puskesmas dan meningkatkan kunjungan ke sekolah dalam pelayanan kesehatan remaja, seperti pendidikan pencegahan perilaku seks bebas.

\section{RUJUKAN}

1. Stanhope M, Lancester J. Community \& Public Health Nursing. 6th ed. Missouri: Mosby Elsivier Inc; 2004.

2. Edelman C, Mandle CL. Health Promotion Throughout The Life Span. St. Louis: Mosby; 2010.

3. Potter PA, Perry AG. Fundamentals of Nursing. 7th ed. Missouri: Mosby Elsivier Inc; 2009.

4. Witjaksono J. Remaja Pelaku Seks Bebas Meningkat 2014 [Internet]. 2014 [cited 2015 Feb 10]. Available from: http://www.bkkbn.go.id/ViewBerita. aspx?BeritalD= 1761.

5. Santrock JW. Psychology Update. New York: The McGraw Hill Companies Inc; 2008.

6. LSCK-PUSBIH. Survey tentang Perilaku seks bebas remaja putri DIY. Yogyakarta; 2008.

7. Jalal F. Bonus Demografi. Makalah disajikan dalam general lekture. Universitas Respati Yogyakarta; 2015.

8. Riskesdas. Badan Penelitian dan Pengembangan Kesehatan. 2010.

9. SDKI. Survei Demografi Kesehatan Indonesia 2012 [Internet]. 2012 [cited 2016 Feb 10]. Available from: http://www.datastatistik-indonesia.com/sdki/.

10. Rahma N. Pusat Pelayanan Keluarga Sejahtera [Internet]. 2014 [cited 2016 Feb 10]. Available from: https://prezi.com/lkl4idwrbw9-/pusat-pelayanankeluarga-sejahtera-ppks/

11. Pander NJ, Murdaugh CL, Parsons MA. Health Promotion in Nursing Practice. Jersey: Prentice Hall; 2002.

12. Santrock JW. Psychology Update. New York: The McGraw Hill Companies Inc; 2005.

13. Ardianto K. Peran Media TV Bagi Remaja. Jakarta: Rajawali Press; 2004.

14. Nuryani I, Pratami FW. Hubungan Keterpaparan Media Informasi Tentang Seks dengan Perilaku Seks Remaja Awal pada Siswa di SMP Semarang. J Din Kebidanan. 2011;1(2):1-11. 